\title{
Compre, leia, siga e rejuvenesça! Sobre os sentidos movimentados e construídos por Veja acerca da velhice ao longo de sua história (1968-2014)
}

\author{
Christa Liselote Berger Ramos Kuschick \\ Felipe Viero Kolinski Machado
}

Resumo: Com base em 2406 edições de Veja (1968-2014), o objetivo do presente trabalho é perceber quais sentidos acerca da velhice (tomada como categoria biológica e discursivamente produzida) são movimentados e construídos pela revista. Mediante pesquisa e inspiração na Análise de Discurso francesa, foram localizados 112 textos abordando o tema e, então, foram coletadas 233 sequências discursivas, permitindo perceber duas Formações Discursivas. De uma forma hegemônica, foi possível observar a consolidação de um discurso que considera a juventude como um valor a ser conquistado, mantido, e a velhice como resultado da inaptidão de cada um. Para Veja, ser jovem seria uma responsabilidade dos leitores, que, ao seguirem suas dicas semanalmente, não envelheceriam.

Palavras-chave: jornalismo; revista Veja; velhice; análise de discurso.

Abstract: Buy, read, follow, rejuvenate! Veja's mobilized and built meanings on aging through History (1968-2014) - This paper aims to grasp the mobilized and built meanings on aging, herein assumed as either a biological category or as a discursively constructed one, and published in 2406 issues of the weekly Veja since 1968 to 2014 . From this total, 112 reports have been detected, out of which 233 speech sequences have been selected, based on the French discourse analysis frames that allow us to understand both discursive formations. Hegemonically speaking, it has been possible to observe a discourse consolidation that considers youth as a value to be conquered and kept still, and aging, on the contrary, as a result of one's inability. According to Veja, being young is under the readers' responsibility, who will never get old if they follow its instructions.

Keywords: journalism, Veja magazine, aging; discourse analysis. 
Nesta faixa [dos 45 aos 55 anos], a deterioração age rapidamente, a qualquer descuido. O cabelo cai depressa, a postura tende a mudar e a pele exige mais. É o último momento para uma primeira cirurgia plástica rejuvenescedora e para o transplante de cabelos, para quem não

pretende chocar amigos e conhecidos e pretende continuar em forma.

(A MEDICINA..., 1981, p. 64) (T13 SD26)

\section{Dos lugares de fala: sobre as bases teóricas que nos inspiram}

O presente texto refere-se à pesquisa desenvolvida no âmbito de nossa dissertação de mestrado, que tinha por objetivo central perceber quais sentidos sobre a velhice foram movimentados e construídos pela revista semanal Veja ao longo de mais de quarenta anos de jornalismo ${ }^{1}$.

Indo ao encontro de Beauvoir (1990), pode-se compreender que, apesar do envelhecimento ser um fato que transcende a história, o envelhecer nem sempre foi encarado da mesma forma, modificando-se mediante o contexto.

Nesta pesquisa, a velhice é percebida como uma categoria que é da instância do biológico e também do social, que é consolidada pelo caráter concreto de um organismo que se modifica com o avançar dos anos e, também, pela materialidade dos sentidos que definem esse corpo.

Podendo, ainda, ser vista como o resultado do investimento do discurso médico sobre o corpo envelhecido (KATZ, 1996), a velhice traz, de modo intrínseco, desde essa origem, as ideias de que a decrepitude seria uma característica invariável desse ponto do ciclo vital e de que, nesse momento, o corpo se degeneraria inevitavelmente. A juventude, em contrapartida, configurando-se em valor, deixa de ser restrita a determinado instante do desenvolvimento e passa a ser meta e desejo, um sonho de uma sociedade que é marcada por um "capitalismo hedonista e permissivo" (LIPOVETSKY, 2005, p. 32).

Em face do crescimento demográfico mundial da população idosa, contudo, todo um mercado buscou enquadrar tais sujeitos, associando imagens menos nebulosas a um nicho comercial em expansão. A terceira idade, a melhor idade e o público sênior (não mais chamado de velho, deve-se destacar), assim, seriam tentativas não de superação de estigmas, mas de uma postergação desses (LENOIR, 1979).

O discurso, por sua vez, tal qual ensina Foucault (2007), é compreendido como o próprio objeto do desejo, como a própria motivação dos sistemas de dominação. Sem um começo e nem um final, o discurso desenrolar-se-ia, envolvendo os sujeitos ao seu redor, em um movimento de sentidos e de significados que instauraria o presente e consolidaria, ao mesmo tempo, uma memória coletiva e as condições necessárias para aquilo que é

1 A dissertação completa, resultante dessa pesquisa, pode ser acessada em: http://biblioteca.asav.org.br/ vinculos/000007/00000705.pdf 
da esfera do devir. Aqui, ainda, através da busca de suas marcas no corpus delimitado, o discurso seria também espaço de observação das disputas ideológicas que assinalam a consolidação dos significados (PÊCHEUX, 1997).

O jornalismo, em face de tais perspectivas, é visto como prática social e discursiva, como um dos lugares em que o agora é narrativizado e, portanto, compreendido coletivamente e como um "discurso revelador/plasmador da sociedade contemporânea" (BERGER, 1996, p. 188). O jornalismo de revista, mais especificamente, possui as suas singularidades, que convêm serem destacadas. Tendo por marca, quando em comparação a outros veículos, uma apuração mais ampla, textos mais longos e um direcionamento a um leitor mais específico e mais familiar (SCALZO, 2008), a revista traria, intrinsicamente, "uma revista dentro da outra ou a revista dentro de si mesma", um "infinito particular, que aciona e é acionado por um jornalismo singular" (TAVARES, 2012, p.05).

A revista Veja, que surgiu como objeto de análise condizente com nossas propostas e questionamentos, foi criada em 1968, pelo Grupo Abril, com o intuito de, por meio da informação, integrar o território nacional. Ao retomar diferentes elementos de sua história (CONTI, 1999; HERNANDES, 2004; MIRA, 2001), pode-se observar uma trajetória não linear, assinalada pela diminuição das vendas e por diferentes mudanças de caráter editorial e estratégico a fim de alcançar, finalmente, o sucesso pretendido.

Contemporaneamente, Veja é a terceira maior revista de informação do mundo e a maior do Brasil. Com uma circulação média que supera um milhão de exemplares, levando em consideração seu efeito multiplicador, acredita-se que seus leitores ultrapassem a marca de dez milhões de pessoas todas as semanas (MEDIA..., [s.d.]).

A escolha por Veja, igualmente, reside no fato de ela possuir um arquivo com mais de quarenta anos de exemplares ${ }^{2}$ (período no qual a velhice passou por muitas mudanças sob um ponto de vista social e político) e no fato dela, progressivamente, ter voltado sua atenção às questões de saúde e de comportamento (HERNANDES, 2004; AUGUSTI, 2005), espaços nos quais, usualmente, enquadrou a temática da velhice.

\section{Da perspectiva teórica e metodológica: sobre a Análise de Discurso francesa e o discurso jornalístico}

A escola francesa de Análise de Discurso (AD), de modo geral, faria referência ao conjunto de trabalhos que, tendo surgido na segunda metade da década de sessenta, associando a linguística estrutural a uma teoria da ideologia, teria ainda forte inspiração na releitura de Marx por Althusser e na psicanálise.

Sobre a noção de ideologia, retomando Althusser (1974, p. 77), seria possível tomá-la como que representando "a relação imaginária dos indivíduos com

2 O acervo com as 2406 edições consultadas encontra-se quase totalmente disponível, materialmente, na Biblioteca Central da UNISINOS, universidade na qual esta pesquisa foi realizada, e totalmente disponível, gratuitamente, no site da revista em questão. 
as suas condições reais de existência" e, ainda, conceber que seria pelo viés da ideologia que os indivíduos seriam interpelados em sujeitos.

Michel Pêcheux (1997), autor mais representativo dessa corrente, ao falar sobre as três épocas que assinalariam o desenvolvimento da $\mathrm{AD}$, ressalta diferentes elementos desse percurso. De um primeiro momento, marcado por uma concepção da produção discursiva como "uma máquina autodeterminada e fechada sobre si mesma" (ibidem, p. 311) e assinalada pelos esquecimentos do sujeito, passa-se a um outro instante em que se atribui uma centralidade ao conceito de Formação Discursiva e à perspectiva de retomada dos já-ditos. A centralidade das questões da heterogeneidade, a qual seria uma característica constitutiva de todo e qualquer dizer, a importância do gesto interpretativo e o caráter de acontecimento do discurso já seriam marcas de uma terceira e última fase (ibidem).

Acerca da noção de Formação Discursiva (FD), torna-se importante discuti-la, uma vez que essa será, posteriormente, no instante das análises, aqui operacionalizada. Para Foucault (2012), uma FD está relacionada à regularidade, à ordem e às correlações que, mediante um certo número de enunciados e um semelhante sistema de dispersão, puderem ser observadas e descritas. Pêcheux (1997), ao estabelecer nexos com aquilo que é exterior a essa formação e ao acionar o conceito althusseriano de ideologia, permite que se desenvolva a perspectiva de que as FDs representariam, na linguagem, as Formações Ideológicas que, então, Ihes seriam correspondentes.

Ao encarar o jornalismo como um discurso que, ao mesmo tempo, é leitor e hiperprodutor de uma grande conversação (FAUSTO NETO, 1999) e como um lugar de circulação e de produção de sentidos (BENETTI, 2008), é compreensível que se recorra à $\mathrm{AD}$ como uma forma possível de se constatar e de se analisar os significados daí provenientes. Para Benetti (ibidem), então, a AD permitiria tanto estudar esses sentidos, por meio das marcas deixadas na superfície textual (objetivo desta pesquisa), quanto empreender, se essa fosse a intenção, um estudo das vozes que comporiam esse discurso.

\section{Do empreendimento das análises: entre sequências e sentidos}

Objetivando perceber os sentidos movimentados e construídos por Veja sobre a velhice, ao longo das 2406 edições analisadas (referentes ao período 1968-2014), restringiu-se o corpus da pesquisa àquelas reportagens que, dentre todas essas revistas, trouxessem a temática de interesse como um dos assuntos centrais.

Dessa forma, a partir da análise individual dos números de Veja aí englobados, chegou-se ao universo de 112 reportagens, distribuídas, não proporcionalmente, ao longo desses mais de quarenta anos de jornalismo e, então, a 233 sequências discursivas (trechos recortados dos textos, a fim de tornar a análise material, dando a ver os sentidos que ali se faziam presentes). A tabela abaixo (tabela 1) traz esses textos, distribuídos ao longo das décadas e seccionados conforme as editorias em que eles foram veiculados. 


\begin{tabular}{|c|c|c|c|c|}
\hline \multirow{2}{*}{$\begin{array}{c}\text { Seção na qual o } \\
\text { texto foi publicado }\end{array}$} & $1968-1979$ & $1980-1989$ & $1990-1999$ & $2000-2014$ \\
\cline { 2 - 5 } Beleza & & & 03 & 12 \\
\hline $\begin{array}{c}\text { Ciência, medicina } \\
\text { ou saúde }\end{array}$ & 06 & 04 & 08 & 18 \\
\hline $\begin{array}{c}\text { Comportamento } \\
\text { Especial }\end{array}$ & 02 & 02 & 03 & 02 \\
\hline $\begin{array}{c}\text { Previdência ou } \\
\text { Aposentadoria }\end{array}$ & & 01 & 01 & 16 \\
\hline
\end{tabular}

Tab.1. Seções de publicação e ocorrência das reportagens por décadas

Fonte: Elaborada pelos autores

Inicialmente, pode-se notar que, com exceção dos anos oitenta, nos quais há uma diminuição em relação ao número de textos publicados no período anterior (19681979), há um crescimento progressivo do número geral de reportagens cuja temática central envolve a velhice. Separando, então, essas quatro décadas em dois grandes grupos, considerando uma questão temporal, é possível constatar que, em seus primeiros vinte anos de existência, Veja publicou apenas 17 reportagens nas quais a velhice correspondesse a um ponto de destaque. Todas as outras 95, cerca de 85\% dos textos coletados, foram publicadas no espaço de tempo 1990-2014.

Mais do que um movimento próprio do veículo, que, nos últimos anos, tende, conforme foi discutido por outros pesquisadores, a uma maior ênfase às questões de saúde, de estética e de comportamento, em detrimento da política e da economia, enfatizadas no período inicial de sua trajetória (AUGUSTI, 2005; CONTI, 1999; HERNANDES, 2004; MIRA; 2001), as justificativas para tais proporções extrapolam meras questões editoriais. Socialmente, a velhice, conforme lembra Debert (1999), vem passando por intensas modificações, chegando a ser reinventada. Em um contexto assinalado pela promoção de um discurso que dota o corpo de características plásticas, apontando-o como maleável conforme o empenho e a dedicação de cada um, e que delimita a juventude como esse valor a ser obtido em qualquer etapa da vida, não é tão surpreendente que o discurso de Veja traga a maior parte de seus textos sobre a velhice circunscritos às questões de ordem estética. Mesmo sob as editorias de Saúde ou de Comportamento, por exemplo, o foco central foram, em geral, as formas de combate e de prevenção ao envelhecimento.

Apesar de discutir a velhice também sob um ponto de vista de interesse público (como ao abordar aposentadorias insuficientes ou mesmo o aumento demográfico do número de idosos), usualmente, contribuiu, conforme será exposto, para a redução da complexidade do tema a procedimentos cirúrgicos rejuvenescedores e a dietas milagrosas.

Algumas sequências discursivas dão a ver os modos pelos quais os sentidos sobre a velhice foram sendo postos em trânsito por Veja. Vale salientar que os textos, assim como 
as sequências discursivas, foram numerados em ordem crescente e essas informações situam-se ao lado de cada trecho aqui reproduzido.

Em 145 clínicas espalhadas pela Romênia, sob orientação da Dra. Ana Aslan, procura-se retardar a velhice. Como método de diagnose usam-se a bioquímica do sangue, os raios $X$, a dosagem das gorduras sanguíneas e a oscilometria - nada de operações. Depois, algumas injeções de procaína, e os velhos se sentem rejuvenescer. (CERCO..., 1973, p. 49) (T05 SD10)

A síndrome de julho não é o único fenômeno a aquecer esse ramo da medicina, impulsionado pela sadia vaidade de pessoas dispostas a retardar os sinais de ação do tempo sobre seus rostos e corpos e pelo desejo manifestado por outros de livrar-se de traços herdados cujos contornos considerem indesejáveis. A cirurgia plástica, no que diz respeito ao desenvolvimento de novas técnicas, vive um período de ouro. (CONSTRUÇÃO..., 1986, p. 60) (T16 SD30)

Haja aeróbica. A academia Competition, uma das mais completas de São Paulo, avalia que uma em cada cinco clientes são mulheres na idade da loba. O índice sobe para $50 \%$ na lista de pacientes dos dermatologistas. Nos consultórios dos cirurgiões plásticos, elas são $60 \%$. O corpo é reconstruído a bisturis, choques elétricos contra a celulite, aluviões de cremes, massagens e malhação. (CAPRIGLIONE; LEITE, 1995, p. 87) (T28 SD59)

Isso mesmo: Madonna, a loira de músculos definidos, magérrima e conservadíssima é cinquentona. Sua figura é fruto de uma dose excepcional de disciplina (e de exercícios), mas estar bem na sua idade não tem nada de incomum. Só no mundo dos artistas, onde a imagem não é tudo, mas chega perto, também acabam de dobrar o cabo dos 50 anos as atrizes Sharon Stone (em março) e Michelle Pfeiffer (em abril), beldades de parar o trânsito em qualquer tapete vermelho. (A AURORA..., 2008, p.98) (T84 SD180)

Dentre algumas das percepções às quais se foi chegando, mediante análise e recuperação de outros trabalhos que com este guardavam alguma semelhança, pode-se destacar o caráter pedagógico (FISCHER, 2002) assumido pela revista. Veja, via citação de estudos e de pesquisas e através de testes e de quadros dirigidos aos leitores (os quais foram intensificados depois da década de oitenta), foi, contínua e progressivamente, delimitando as formas adequadas de se portar e de se viver, apontando o que viria a ser, para ela, um "envelhecimento saudável" e, então, como obtê-lo. Desenvolveu, assim, um verdadeiro receituário performativo, conforme sugere Prado (2009), em que os enunciadores-cartógrafos, sempre especialistas, poderiam designar os melhores caminhos a serem seguidos. 
Para quem faz questão de ser bonita, manter a forma é uma luta que dura toda a vida. Mas existem alguns cuidados que devem ser tomados desde cedo e problemas que só surgem em determinadas etapas da existência. Fazer ginástica ajuda a manter o peso e a elasticidade da pele. Já foi criada até uma série de exercícios para manter o rosto sem rugas. Para fazê-los, basta articular, forçando os músculos da face, as cinco vogais nessa ordem: A, O, U, E, I. (A MEDICINA..., 1981, p. 64) (T13 SD 24)

Igualmente, é importante ressaltar que Veja, ao relacionar a velhice ao declínio físico e à perda de valores estéticos, situa em diferentes lugares homens e mulheres. Indo ao encontro de Attias-Donfut (2004), que, ao falar em envelhecimento masculino e feminino, diz que, no seio de uma sociedade machista, o frescor, a beleza e a doçura são cobrados muito mais da presa do que do predador, Veja não se omite ao ressaltar o charme de algumas marcas para eles e a premência de evitá-las para elas.

Como cabelo grisalho e rugas discretas nunca foram impedimentos para o sucesso social masculino, permanecem galãs (ou por causa) da idade madura os irresistíveis Pierce Brosnan, um poço de charme aos 55 anos, Richard Gere, inalterável jeitinho carente aos 58, e José Mayer, que aos 59 e longe de sua melhor forma (por força do papel, ressalta-se), anda aos beijos com Juliana Paes em A favorita, folhetim das 8 da Globo. (A AURORA..., 2008, p.99) (T84 SD181)

Sabendo-se, portanto, que, depois dos 60, lipo ondula, lifting estica demais, Botox paralisa e preenchimentos inflam em excesso, conclui-se que fórmula perfeita para o bem envelhecer não há. Ou melhor, há, só que é privilegio de pouquíssimas - quem diz que Suzana Vieira, capaz de tirar de letra cenas tórridas de paixão em novelas, tem 64 anos? Ou então é questão de encarar a passagem dos anos da melhor forma possível, exibindo rugas e cabelos brancos com pose e altivez, como faz, aos 80 anos, a rainha Elizabeth da Inglaterra - provavelmente a única milionária do planeta que jamais se submeteu a uma cirurgia plástica. (ALISAR..., 2007, p. 93) (T78 SD167)

As tensões entre uma velhice temerosa (em geral asseverada pela aparência física indesejada) e uma terceira idade positiva (sempre assinalada pelas possibilidades de consumo) também se manifestaram no discurso de Veja, dando a ver questões como uma escassez de discursos sobre a pauperização na velhice (em especial mais contemporaneamente) e a apresentação de um envelhecimento positivo sempre como reflexo das ações de cada um (tanto no que tange à prática de exercícios físicos quanto às possibilidades financeiras de se viajar continuamente, como hobby).

Quem se cuida vai empurrando a velhice com a bem malhada barriga, como atesta o analista financeiro Juarez Aguilar, 47 anos. Ele passa três horas por dia numa academia de ginástica em São Paulo. "Chego em casa muito mais disposto para 
namorar", afirma ele, que cortou frituras e gasta 200 reais por mês em suplementos vitamínicos com apoio da mulher, Salete. (VEIGA, 2000, p. 124) (T48 SD94)

Tendo em vista aquilo que foi coletado e analisado, foi possível constatar dois grandes núcleos de sentido, dentro dos quais, em diferentes momentos e de diferentes modos, sentidos comuns foram reiterados por Veja. Em consonância com a perspectiva teórica e metodológica aqui acionada, compreende-se que essas duas categorias correspondem a Formações Discursivas, uma vez que, sob essa lógica, tratariam daqueles dizeres que, continuamente retomados e reforçados, estabeleceriam os significados possíveis de serem estabelecidos e, para além do plano do texto, dariam a ver as disputas ideológicas que cercariam a questão.

A tabela a seguir (tabela 2) expõe, portanto, as Formações Discursivas percebidas, o número de sequências que cada uma agrega e a sua ocorrência.

\begin{tabular}{|c|c|c|}
\hline Formação Discursiva (FD) & \multicolumn{1}{c|}{$\begin{array}{c}\text { Número de } \\
\text { sequências } \\
\text { discursivas }\end{array}$} & $\begin{array}{c}\text { Ocorrência } \\
\text { percentual }\end{array}$ \\
\hline $\begin{array}{c}\text { Formação Discursiva 01 } \\
\text { Velhice como questão privada }\end{array}$ & 171 & $73,40 \%$ \\
\hline $\begin{array}{c}\text { Formação Discursiva 02 } \\
\text { Velhice como questão pública }\end{array}$ & 62 & $26,60 \%$ \\
\hline
\end{tabular}

Tab. 2. Formação Discursiva, número de sequências englobadas e ocorrência Fonte: Elaborada pelos autores

A FD que se mostrou dominante, uma vez que agregou mais de setenta por cento das sequências coletadas em todo o período de análise, permitiu que uma velhice muito específica fosse constituída e consolidada nas páginas de Veja. Não se trata da velhice do número crescente de idosos, tampouco da velhice pauperizada à qual estão submetidos muitos velhos brasileiros, mas da velhice que é de uma esfera privada, de um processo de envelhecimento que está nas mãos dos sujeitos que o vivenciam diariamente e que, portanto, possuem meios de torná-lo menos agressivo ou até mesmo de impedi-lo. Trata-se de um discurso que tende a reprivatizar a velhice (DEBERT, 1999).

Torna-se interessante salientar que, ao serem cruzados os dados da tabela um e dois, constatou-se que o único período no qual Veja abordou, majoritariamente, uma velhice que não se restringisse à estética foi na sua primeira década de existência (1968-1979), dando a ver que, em algum momento, sua postura foi outra. Apesar disso, em todos os outros períodos, e de forma ainda mais intensa nos seus últimos anos (2000-2014), dificilmente ultrapassou aspectos dessa ordem.

O KH-3, uma espécie de fonte da juventude que cientistas alemães descobriram em seus laboratórios e conseguiram comprimir numa pequena cápsula, está entrando no Brasil pela porta do contrabando. No Rio o seu consumo entre 
as pessoas de idade já começa a se transformar em moda: por 250 cruzeiros novos consegue-se uma caixa de 150 cápsulas - e alguma esperança. (JUVENTUDE..., 1969, p.47) (T01 SD01).

Para quem não se preveniu a tempo e já exibe os sinais da passagem dos anos, a cosmeatria e a cirurgia plástica desdobram-se em criatividade, novas ideias e técnicas mais apuradas. Em matéria de bisturi, a ideia geral também é fazer intervenções mais precoces, quase preventivas, e menos traumáticas (VIVER..., 1993, p.91) (T25 SD50).

Mais significativo do que aumentar o ciclo vital é o fato de que o bem-estar e a própria aparência da juventude podem ser prolongados por muito mais tempo. A medicina, os estudiosos do metabolismo e os pesquisadores da nutrição e da fisiologia têm atualmente recursos para atrasar o relógio biológico humano. Um homem de 70 anos pode ter hoje o desempenho intelectual, físico e sexual semelhante ao que teve aos 40 anos. Uma mulher de 50 pode ter a pele lisa e suave que desfrutava aos 30 anos (NEIVA, 2006, p.93) (T75 SD154).

Para além desse núcleo de sentidos, contudo, uma segunda FD também foi percebida. Com um total de 62 sequências, e uma representatividade da ordem de $26,60 \%$, ela construiu espaços para uma velhice pública, de características coletivas e sociais.

Aspectos sobre a velhice que ultrapassam a esfera privada, concernentes, por exemplo, ao governo, foram aqui englobados. Questões como aposentadoria, legislação específica, aumento demográfico do número de idosos e sobrecarga da previdência tiveram vez, opondo-se à perspectiva que toma a velhice meramente como relativa ao sujeito. A terceira idade, tomada como fase positiva, gerando impacto social, também foi o foco em alguns textos. As sequências abaixo ilustram tais pontos.

Do completo desconhecimento das aspirações que pudessem motivar esse contingente de 5 milhões de pessoas, vive-se agora o período das primeiras certezas. Já se sabe, por exemplo, que, embora arredio aos contatos iniciais com outros parceiros da mesma faixa etária, o idoso acaba por integrar-se completamente a grupos, clubes, equipes, que simplesmente realizem bailes, ou se dediquem à fabricação de artesanato, ou até se reúnam para lembrar os tempos da mocidade. [...] A descoberta das possibilidades do que os gerontólogos chamam de 'terceira idade' tem sido, na verdade, o grande denominador comum a todos os movimentos pró-idosos (VIVENDO..., 1976, p. 94) (T08 SD16).

'Se o estado desse uma aposentadoria decente e fornecesse assistência às famílias dos idosos, os velhos brasileiros estariam em melhores condições', afirma a gerontóloga e psicanalista paulista Elvira Abreu e Melo Wagner (DIREITO..., 1993, p. 70-71) (T24 SD46). 
Em 2050 haverá apenas três pessoas em idade potencialmente produtiva para cada uma com 65 anos ou mais. É uma proporção que torna impossível financiar o sistema. E o mais preocupante é que o Brasil tem andado na contramão, insistindo num modelo de cobertura muito amplo, em vez de restringir o acesso aos benefícios (VENTUROLLI, 2004, p. 108) (T67 SD139).

\section{Das conclusões: o que o "veículo indispensável" tem a dizer sobre a velhice?}

A partir da leitura das reportagens, das sequências discursivas coletadas e das Formações Discursivas então percebidas, foi possível constatar um movimento contínuo, mas com maior fôlego após a década de noventa, no sentido de reprivatizar a velhice, ou seja, reduzi-la a uma série de questões de ordem individual, particular (DEBERT, 1999).

Avanços na área da medicina estética e um maior conhecimento do organismo humano, acionados pela revista, poderiam, então, fornecer aos seus leitores atentos o elixir da vida longa e saudável. Uma dieta balanceada (e, mais contemporaneamente, com restrições ao consumo máximo de calorias diárias), exercícios físicos constantes (aeróbica, musculação, natação), hábitos de consumo (por que não usar a mesma saia que a filha?) e uma vida ativa poderiam gerar mudanças entre a idade verdadeira (marcada no calendário) e a idade real (idade do corpo), conforme ensina Michael Roizen, médico que se torna espécie de guru para Veja nos anos 2000.

Ser jovem, sob tal percepção, não corresponderia a uma característica de dado estágio do desenvolvimento biológico, mas, ao invés disso, em um ideal a ser cotidianamente buscado e desejado. Na corrida pela manutenção da juventude e pelo adiamento da velhice, entretanto, conforme ressalta Veja em alguns momentos, nem todos largariam do mesmo ponto. Homens e mulheres, por exemplo, correriam em pistas diferentes. Afinal, de acordo com a publicação, se, por um lado, as rugas de Richard Gere são um charme a mais do galã americano, os cabelos brancos da maior parte das mulheres continuam sendo vetados por remeterem ao anátema supremo: a velhice.

Do mesmo modo, embora em pouquíssimos casos problematize essa questão, entre pobres que sobrevivem com um sistema público de saúde muitas vezes ineficaz e ricos que podem, a cada dez anos, recorrer a um cirurgião plástico para pequenos retoques, existe um grande abismo social que se reflete diretamente nas experiências de velhice ou de não-velhice.

Nesse cenário, o corpo, então, deve ser diluído, não deve chamar a atenção pelas suas características negativas. Por outro lado, o imperativo da forma exige que ele seja exposto. "Fique nu", é dito, ao passo que se acrescenta: "mas seja jovem!".

Dessa maneira, tendo em vista os sentidos que mobiliza e reforça, Veja dá a ver a articulação de um biopoder (FOUCAULT,1988) que, se dirigindo aos corpos dos indivíduos, visa ensinar o homem a portar-se como ser vivo, ao passo que objetiva otimizar 
suas chances de viver mais e melhor. Não apenas dizendo de práticas bio-ascéticas, mas as legitimando e apontando a relevância de que sejam seguidas pelos leitores, a revista sanciona a premência de sujeitos plurais serem inseridos no formato único da juventude.

Em um mar de incertezas, o homem/mercadoria pós-moderno de Bauman (1998; 2008) clamaria por definições, por uma rota segura que lhe garantisse a longevidade e os prazeres da não-velhice. O jornalismo, então, e o jornalismo de Veja, analisado aqui, assume o papel de conselheiro, reveste-se em manual de comportamento e, pedagogicamente, ensina aos seus leitores como as vidas devem ser tocadas (FISCHER, 2002).

Em contrapartida, torna-se pertinente salientar, os discursos não são proferidos em uníssono e, invariavelmente, na disputa simbólica e material em torno do sentido, existem espaços para dizeres que são de outra instância, para aqueles significados que vêm de outros lugares.

A segunda Formação Discursiva localizada neste trabalho, "Velhice como questão pública", sinaliza empiricamente essa perspectiva. Apesar de minoritária, as sequências que compõem a FD02 movimentam e estruturam sentidos que se opõem àqueles presentes na FD01. De uma velhice de tons privados, cuja administração caberia a cada um, chegase, aqui, a uma velhice cuja responsabilidade extrapola os hábitos e as vontades pessoais. A participação do Estado, então, passa a ser percebida como essencial para que a maior parte dos sujeitos possa ter uma vida longeva e plena. Igualmente, quando aqui inserida, a velhice passou a ser vista como uma questão de interesse público, englobando o aumento demográfico do número de idosos e as revoluções propiciadas pelo desenvolvimento da terceira idade.

Hegemonicamente, apesar disso, mediante análise de reportagens de seus quarenta e seis anos de jornalismo, pode-se dizer que Veja, que se intitula como "indispensável" ao cidadão brasileiro, movimenta e constrói sentidos sobre uma velhice de tons muito restritos. Se tomarmos o jornalismo como uma forma de conhecimento, tal qual sugere Meditsch (1998) e pensarmos ainda no potencial de construção de outros mundos possíveis, por um jornalismo pautado pelo interesse público, podemos pensar que Veja, no que tange à questão aqui analisada, falha miseravelmente. Em contrapartida, se desejamos um arquivo sobre práticas rejuvenescedoras, que diga do sonho de uma não-velhice eterna, então, teremos na maior revista do Brasil um excelente material de consulta.

Christa Liselote Berger Ramos Kuschick é professora titular do Programa de Pós-Graduação em Ciências da Comunicação da Unisinos. Coordena o grupo de pesquisa Estudos em Jornalismo e é coordenadora nacional do Procad - Tecer: jornalismo e acontecimento. É pesquisadora $1 \mathrm{~B}$ do CNPq. Fez estágio de Pós-Doutorado em Teorias do Jornalismo na Universidade Autônoma de Barcelona - UAB (2003).

christabergerk@yahoo.com.br 
FelipeViero Kolinski Machado é doutorando do Programa de Pós-Graduação em Ciências da Comunicação da UNISINOS e bolsista CAPES. Atualmente, realiza estágio doutoral com bolsa CAPES/PDSE junto ao Centro em Rede de Investigação em Antropologia (CRIA/ISCTE-IUL), em Lisboa/Portugal, sob a orientação do Prof. Dr. Miguel Vale de Almeida.

felipeviero@gmail.com

\section{Referências}

ALTHUSSER, Louis. Aparelhos Ideológicos do Estado. Lisboa: Editorial Presença/Martins Fontes, 1974.

AUGUSTI, Alexandre. Jornalismo e comportamento: os valores presentes no discurso da revista Veja. Dissertação de Mestrado. Programa de Pós-Graduação em Comunicação e Informação. Porto Alegre: Universidade Federal do Rio Grande do Sul, 2005.

ATTIAS-DONFUT, Claudine. Sexo e Envelhecimento. In: PEIXOTO, Clarice Ehlers. Família e Envelhecimento. Rio de Janeiro: Editora FGV, 2004.

BAUMAN, Zygmunt. O mal-estar da pós-modernidade. Rio de Janeiro: Jorge Zahar, 1998.

Vida para consumo: a transformação das pessoas em mercadoria. Rio de Janeiro: Zahar, 2008.

BEAUVOIR, Simone de. A velhice. 6a reimpressão. Rio de Janeiro: Nova Fronteira, 1990.

BENETTI, Márcia. Análise do Discurso em jornalismo: estudo de vozes e sentidos. In LAGO, Cláudia; . (Org.) Metodologia de pesquisa em jornalismo. 2a ed. Petrópolis: Vozes, 2008.

BERGER, Christa. Em torno do discurso jornalístico. In: FAUSTO NETO, Antonio; PINTO, Milton José (org.). O indivíduo e as mídias. Rio de Janeiro: Diadorim, 1996.

CONTI, Mario Sergio. Notícias do planalto: a imprensa e Fernando Collor. São Paulo: Companhia das Letras, 1999.

DEBERT, Guita Grin. A Reinvenção da Velhice: Socialização e Processos de Reprivatização do Envelhecimento. São Paulo: Editora da Universidade de São Paulo; FAPESP, 1999.

FAUSTO NETO, Antônio. Comunicação e mídia impressa: estudo sobre a AIDS. São Paulo: Hacker, 1999.

FISCHER, Rosa Maria Bueno. O dispositivo pedagógico da mídia: modos de se educar na (e pela) TV. In: Educação e Pesquisa, São Paulo, v. 28, n.1, p. 151-162, jan./jun. 2002

FOUCAULT, Michel. A arqueologia do Saber. $8^{\mathrm{a}}$ ed. Rio de Janeiro: Forense Universitária, 2012.

História da sexualidade I: a vontade de saber. Rio de Janeiro: Edições Graal, 1988.

. A Ordem do Discurso. Aula Inaugural no Collège de France, pronunciada em 2 de dezembro de 1970. 15 ed., São Paulo: Loyola, 2007.

HERNANDES, Nilton. A revista Veja e o discurso do emprego na globalização: uma análise semiótica. Salvador: EDUFBA; Maceió: EDUFAL, 2004.

KATZ, Steven. Disciplining old age: the formation of gerontological knowledge. Charlottesville: University Press of Virginia, 1996.

LENOIR, Rémi. L'invention du «troisième âge». In: Actes de la recherche en sciences sociales. Vol. 26-27, mars-avril 1979. p. 57-82. 
LIPOVETSKY, Gilles. A era do vazio: ensaios sobre o individualismo contemporâneo. Barueri: Manole, 2005.

MEDIA KIT VEJA. Download do arquivo disponível em: <http://www.publiabril.com.br/marcas/veja/ revista/informacoes-gerais>. [s.d.] Acesso em: jul. de 2014.

MEDITSCH, Eduardo. Jornalismo como forma de conhecimento. In Revista Brasileira de Ciências da Comunicação. Identidades comunicacionais. São Paulo, vol. XXI, n. 1, janeiro/junho. p. 25-38, 1998.

MIRA, Maria Celeste. O leitor e a banca de revistas: a segmentação da cultura no século XX. São Paulo: Olho d'Água/ Fapesp, 2001.

PÊCHEUX, Michel. A análise do discurso: três épocas. In GADET, Françoise e HAK, Tony (Orgs.) Por uma análise automática do discurso: uma introdução à obra de Michel Pêcheux. Campinas: UNICAMP, 1997.

PRADO, José Luiz Aidar. Experiência e receituário performativo na mídia impressa. In: InTexto. Porto Alegre: UFRGS, v. 1, n. 20, p. 34-47, 2009.

SCALZO, Marília. Jornalismo de revista. São Paulo: Contexto, 2008.

TAVARES, Frederico de Mello Brandão. Mise en abyme e editoração: sobre o jornalismo de revista e seu infinito singular. In: XXI Compós - Encontro da Associação Nacional dos Programas de PósGraduação em Comunicação, 2012, Juiz de Fora. Anais do XXI Compós. Juiz de Fora: Universidade Federal de Juiz de Fora, 2012. v. 21, p. 1-17.

\section{Corpus de referência}

A AURORA dos cinquentões. Veja. São Paulo: editora Abril, ano 41, ed. 2068, 2008.

ALISAR ou não alisar. Veja. São Paulo: editora Abril, ano 40, ed. 1990, 2007.

A MEDICINA da beleza. Veja. São Paulo: Editora Abril. Ano 14, ed. 658, 1981.

CAPRIGLIONE, Laura; LEITE, Virginie. A batalha começa aos quarenta. In: Veja. São Paulo: editora Abril, ano 28, ed. 1399, 1995.

CERCO à velhice. Veja. São Paulo: editora Abril, ano 06, ed. 252, 1973.

CONSTRUÇÃO da beleza. Veja. São Paulo: Editora Abril. Ano 19, ed. 933, 1986.

DIREITO ao futuro. Veja. São Paulo: editora Abril, ano 26, ed. 1287, 1993.

JUVENTUDE agora em pílulas. Veja. São Paulo: editora Abril, ano 02, ed. 21, 1969.

NEIVA, Paula. As idades do corpo. In: Veja. São Paulo: editora Abril, ano 39, ed. 1957, 2006.

VEIGA, Aida. Sexo depois dos 40 (agora fora das telas). In: Veja. São Paulo: editora Abril. Ano 33, ed. 1650, 2000.

VENTUROLI, Thereza. Viver mais e melhor. In: Veja. São Paulo: editora Abril. Ano 37, ed. 1871, 2004.

VIVENDO a terceira idade. Veja. São Paulo: editora Abril. Ano 06, ed. 428, 1976.

VIVER bem é a melhor vingança. Veja. São Paulo: editora Abril. Ano 25, ed. 1306, 1993.

Artigo recebido em maio e aprovado em outubro de 2015. 